\title{
Egyptian E-Learning University: Case Study
}

\author{
Yasser H. Dakroury \\ Professor of Computer Engineering, Ain Shams University \\ Managing Director of the Egyptian E-Learning University Project
}

\begin{abstract}
This paper introduces a case study of the Egyptian E-Learning University (EELU) as the first higher education institution in Egypt that adopts e-learning model for teaching and learning. The EELU case study presents the experience of applying the characteristics and framework of e-universities. The objective of the author is to help the reader understand what has been set out to do and how, and to convey lessons learned. The paper begins with an introduction section to familiarize the reader with the university. The following sections are about E-Learning Definitions and concepts, Characteristics of an efficient E-Learning, and E-University Framework applied to EELU. The paper ends with a conclusion and lessons learned.
\end{abstract}

Index Terms - E-Learning, Distance Learning, Virtual University, Online Education, Education Technology, Open Education

\section{INTRODUCTION}

$\mathrm{T}$ He Egyptian E-Learning University (EELU) is a private non-profit University that provides distance education through 24-hour online learning with a vision to be a leading university providing e-learning nationally, regionally, and internationally. EELU gives educational opportunities to learners who cannot attend a campus university. The system of education is based on credit hours. Students are required to complete a certain number of credit hours to satisfy the graduation requirements. EELU provides professional continuing education and training programs. The university provides e-learning services by which students can access courses' materials, lectures, virtual classrooms, and any information through both the EELU Intranet and the Internet. As E-learning is the core of the university, it is important to define its concepts and present its main features and framework.

\section{E-LEARNING DEFINITIONS AND CONCEPTS}

E-learning is the use of technology to create, deliver and facilitate learning, anytime, anywhere. It includes education, training, or knowledge management. It uses a technological means (Computer, Internet, Intranet, Extranet, ... etc.) to access and manage learning that supports and enhances the knowledge of an individual. This includes web- based learning (WBL) and computer-based learning (CBL). E-learning components may include web-based teaching materials, and hypermedia in general, multimedia CD-ROMs, websites, discussion boards, collaborative software, email, chat rooms, learning management software, computer-aided assessment, educational animation, simulations, and more, with possibly a combination of different methods being used.

Education is a structured event specifically intended to develop durable knowledge and skills. Traditional classroom represents a type of learning called formal learning which is described as teacher-centered; it has stated objectives and is supported to yield predetermined results. In a classroom, the instructor is a person. E-learning, which is described as learner-centered, recreates the formal learning experience online. Elearning supports online education and online training. In both online education and online training, the computer becomes the instructor. Another option of formal learning is the blended learning which is a combination of e-learning and traditional learning systems. 


\section{Characteristics of AN EFficient E-Learning}

E-Learning should be delivered in an effective cost, be flexible and scalable. An efficient e-learning must include the following six critical factors:

1. Leverage in-place-network and computing infrastructure.

2. Integrate required collaborative and learning specific tools.

3. Support the main learning modes: self-paced (synchronous) and live (asynchronous) under a single, consistent, easy to use interface.

4. Include the management tools to provide a robust registration system, comprehensive assessment features, and system monitoring capabilities.

5. In content neutral for easy reuse of existing content or creation of new content.

- Content must be easily sequenced into courseware by using appropriate tools.

6. Easily scales to support thousands or tens of thousands of users.

- Incremental cost of ownership is dropped as additional users are brought on board.

The e-learning has the following major advantages:

- Access: anytime, anywhere concept makes education and training more available to learners.

- Cost: Reducing education and training costs.

- Efficiency: Avoiding scheduling of classrooms and booking instructors.

- Empowerment: putting the responsibility for learning in the hands of learners.

- Business: Using fast, effective learning as a competitive edge.

- Convenience: Letting time-pressured students learn at the best time and place.

- Content: Increasing the scope of offerings.

Speed: Responding to constant and rapid changes

\section{IV.1Institutional Development and Organization}

An institutional model should be developed to reflect the vision of the institution, its mission, policies, and goals. Leadership, commitment and support from senior management are essential to the creation of a new institution or change in an existing one. The development of ICT-supported environment for teaching and learning implies significant institutional change, vision and leadership from senior level.

An institutional process with policies and procedures has to be developed, documented and used. The process documentation implies best practices and lessons learned from previous implementation either in the institution itself or in similar institutions. The process should be monitored and evaluated to have a continuous process improvement environment. A formal organizational structure has to be developed to suit the newly created jobs.

Finally, it is needed to identify information, dissemination, and a marketing strategy to explain the elearning mode of education as well as promoting the services. Hence, Egyptian E-Learning University has developed an Institutional model that reflects all the aspects of a successful organization. 


\section{A. EELU Mission}

The mission of the Egyptian E-Learning University is to provide high-quality education at affordable price and to produce industry ready knowledge workers. We are committed to create and continuously improve teaching and learning environment that is most effective and efficient to meet future needs of

industry and society. EELU offers High-quality educational services anywhere, anytime. To achieve its mission, the EELU is to provide a virtual educational environment that reduces dependence on the concept of physical and geographical proximities between student and teacher and in the mean time provide maximum educational interactions, benefits and management.

\section{B. EELU Policies}

- Admission: EELU admits students with high school certificate or the equivalent, and the transferred students from other accredited institutions.

- Language of Teaching: English is the language of instruction in all faculties, so students must be proficient in it. An intense program of English language enhancement is available to achieve this goal.

- Education System: The system of education is based on credit hours. Students are required to complete a certain number of credit hours to satisfy the graduation requirements.

- Scholarships: EELU offers scholarships for distinguished applicants and excellent students. A student aid has been undertaken to serve a broad range of students in a flexible manner rather than focusing on financially privileged students. The principle is that fees may not constitute a barrier for students' access to higher education.

\section{EELU Goals}

EELU has been established to achieve the following goals:

- Enhance the quality of higher education using modern technologies, create a broad information technology base, use modern e-learning modalities, and promote the university's e-governance.

- Participate in improving Egypt's higher education participation ratio by increasing total student enrollment.

- Provide its graduates with the knowledge and skills that ensure high employability, and provide opportunities for professionals to excel in their careers.

- Offer distinguished education in modern and inter-disciplinary educational areas to have capacity for the future needs in human resources at both the local and regional levels.

- Provide those, who are unable to attend traditional regular universities, with an opportunity to have university education.

- Establish a strong line of research in technology-related areas, and establish links with reputable research centers worldwide.

\section{EELU Sponsorship}

A direct sponsorship and commitment from the Egyptian Minister of Higher Education and the Cabinet are provided to support all the activities of the University.

\section{E. EELU Organizational Structure}

A formal organizational structure has been created to include all the necessary academic, technical, and administrative jobs. The organizational structure implies jobs titles, objectives, descriptions, responsibilities, needed skills and qualifications. Furthermore, newly created jobs related to the following entities are defined:

- Information and Communications Technology Center.

- Education Technology Center.

- E-Courses Production Center. 


\section{- Help desk Service.}

Therefore, the EELU organizational structure illustrates the existing of an ICT-supported environment for teaching and learning.

\section{F. $\quad$ Marketing strategy}

A detailed strategy for EELU marketing campaign has been drawn in order to introduce the university and its educational services to the community. The main goals of the advertising campaign focus on presenting the concept and the characteristics of the e-Learning, defining it, and making it convincing and trustable by concentrating on the advantages and the flexibility of this mode of learning and the knowledge values which e-learning add to a student. In addition to defining the objectives of the university, its policies, and academic and training programs which the university provides in order to attract a huge number of students.

The marketing campaign also focuses on the special educational services of the university which satisfy the educational needs of the society scientifically and financially better than the traditional universities (governmental universities) or the competing universities (like the private universities and open universities).

\section{Pedagogical Approach}

In learning situation, there are various approaches can be used in combination. The challenge is to find the right balance. An instructor can see these approaches as tools. A good pedagogue knows when to choose what tool and how long to use it. The following are the three main approaches:

1. Instructional: Emphasis is on "getting the message across" from the information source to the students. The main way of communication is one way. The teacher controls what is delivered, and decides pacing and process. Therefore, this approach is called teacher-centered. The information taught is often "decontextualised" i.e. the student studies for the sake of studying in a classroom or school setting, as opposed to "contextualized" learning where a student has to learn something in order to solve a problem or assignment connected to real life, may be even outside the school situation.

2. Constructivism: This approach argues that people have to be active learners and construct knowledge themselves based on what they already know. The approach is often problem-based learning. The student is given a task or a problem to solve. The student must decide the process to solve the problem or task. S/he must find the resources and tools and decide how to use these resources. The individual student may choose to learn in isolation or obtain interaction and feedback from peers and/or a mentor or tutor.

3. Social Constructivism: This approach means that the student joins a knowledge-generating community and in collaboration with others solves real problems and assignments. Learning takes place where newcomers meet and interact with peers. The tasks will be processing and assessing knowledge, negotiate meaning and generating and co-constructing new knowledge. Learning is a social activity where the students have to use the information the gather actively by applying it in discussion with others.

EELU adopts a pedagogical model that combines the three above mentioned approaches. The instructional model is supported by traditional face-to-face classes which represents around $25 \%$ of the total teaching hours per course. The constructivism and social- constructivism models are supported through exercises, researches, projects that are implemented by students in individual- basis and/or group basis.

\section{IV.3 Technology}

Technology is central to most of the functions of an e-university, both the technological infrastructure that supports the operation of the whole institution, and that supporting the teaching and learning function. The stability of the system and the scope of the support given to the users are critical. Services must always be there when users need it, that is $7 / 7$ and 24/24. Since one of the main advantages of ICT-supported 
An infrastructure planning must consider the following:

- Network infrastructure: Intranet/Internet.

- Hardware: adequate performance.

- Software: support teaching and learning model effective with user-friendly interface and easy navigation.

- Delivery Approach: satellite, Internet, Hybrid model.

- Support to the administrative functions.

- Linux and open source software versus commercial software licenses.

- Cost, support, flexibility, integration with other software packages and applications.

- Access Control/Security/ Performance tuning applications.

A proper maintenance of the technological infrastructure implies that hardware and software are updated on a regular basis and that this can be managed within the annual budgetary planning and allocation process. A trained technical staff must be there to support students and staff.

\section{A. Network Infrastructure}

EELU has an intranet that connects its learning centers, in Cairo and other governorates, via highspeed communication links. A high-speed Internet connection is established via an Internet Service Provider.

\section{Hardware/Software Infrastructure}

The Hardware depends on multi-type platforms: Unix and Windows. The Unix platform provides high availability, security, and fast response to critical-mission applications like Learning Management System, Contents Management System, Portal, e-mail, ... etc.

Windows platforms used to provide flexibility and easy- to- use for the administration, virtual classrooms, management applications, etc.

The software depends on proprietary commercial software to be supported by the intended companies. The decision was taken in favor of commercial software versus open source to provide a great chance of success in the opening phase.

\section{B. Video Conferencing}

This service allows for conducting meetings, lectures, interviews between the EELU main campus and its learning centers in an interactive real-time environment supported by video and audio communication. Lectures are also available to be downloaded using video on-demand (VOD) service.

\section{Virtual Classrooms}

This service enables students to attend classes anywhere. Also, these classes are recorded to be replayed later on by students to follow-up their lectures through the Internet anytime and anywhere.

\section{Technology Training}

An appropriate training program on operating and maintaining the networks (LAN, intranet, Internet), hardware, software, and other technological components has been delivered to the technical staff.

\section{IV.4 Academic programs and Courses design}

Choice of programs and courses must be made carefully in order to ensure that subjects are suited to the type of planned delivery and respond to demand. Feasibility study is recommended as e-learning education requires high initial investment that can only recovered with significant number of students. Highquality programs are the pre-requisite for high student enrolment. 
The pedagogical model needs to accommodate different types of learners to face increasingty diversified student profile. It is essential to plan for and support staff development through well-designed training program on e-learning and virtual university environment.

Student support services need to be of high quality to ensure the success of learners. Quality Assurance and Accreditation are needed:

- A good instructional design system combined with external peer review and accreditation are important.

- The development of courses by teams of academics and professionals is recommended.

- Comprehensive students'services are essential.

\section{A. Course Development Methodology}

EELU follows a five-phase course development methodology. These phases are:

1. Course Planning.

2. Course Production.

3. Delivering and Tutoring.

4. Evaluation of Teaching and Course Materials Effectiveness.

5. Course Revision.

The e-courses production center is composed from different professional experts and profiles that contribute with their own specific competencies to the courses development. The cooperation among subjects with different competencies in different fields, each of which is in charge of a specific phase of the production process, grants an excellent result. The major roles are defined as follows:

- $\quad$ Project manager.

- Subject matter expert.

- Instructional designer.

- Content developer.

- Media coordinator.

- Graphic artist.

- Courseware engineer.

- Quality coordinator.

An e-course delivery policy is to have 3A courses: study Anytime, Anywhere, At your own pace. The copyright policy has been stated clearly; all the educational materials and ecourses are EELU copyrighted. Other related policy issues like the accreditation and recognition of credentials (nationally and internationally) are currently in the process of development.

\section{B. Undergraduate Programs}

EELU offers the following undergraduate programs:

1. Computer and Information Technology.

2. Business Administration.

3. Mass Communication.

4. Languages and Translation.

5. Economics and Political Sciences.

6. Engineering and Technology.

7. Education.

8. Law and Legal Studies. 


\section{Research Centers}

To support graduate studies and to have a liaison with the industry, EELU creates two research centers:

1. Center for scientific and technological innovation.

2. Technological incubators.

\section{Continuing education and Training programs}

EELU provides professional continuing education and training programs to meet the needs of wide variety of adult learners and organizations.

\section{IV.5 Evaluation}

Different methods are used to evaluate students.

- Computer-based exams versus paper-based.

- Centralized versus decentralized.

- Same exam in a specific time versus different exams in different times (students may be in different time zones).

- Supervision policy.

Also, an evaluation must be provided by students to cover different issues regarding the following:

- Content.

- Instructor.

- Learning environment.

- Learning Resources.

- Course Design.

- Technical, Academic and Administrative Support.

Students are evaluated using different methods:

- On-line exams on multiple weeks of the semester.

- Assignments, exercises, mini-projects are used to support the coursework evaluation.

- Time of communication with e-courses throughout the learning management system.

- A supervised exam approach is used to evaluate students in the end-of-semester exam.

\section{IV.6 Management}

An organizational structure and all the management practices have to be developed. The organizational structure must consider the following areas and domains:

- Academic Affairs:

- Quality Assurance and Accreditation.

- Administrative Affairs:

- Remote students and staff.

- Response within certain time limits.

- Students Services and Affairs:

- Instructor

- Tutor

- Technical Staff

An appropriate technical and administrative infrastructure should be there to support the implementation of the management practices. This includes the following:

- Assigned Responsibilities.

- Provided Resources.

- Training of academic, technical and support staff.

- Monitor and control the quality of practices. 
- Adequate financial Resources:

- Be prepared to invest and do not expect immediate returns.

- Review status with top-level management.

- Modern management and accountability methods.

- Flexibility in coordinating the different players involved.

\section{A. Academic Staff Training}

A training program has been developed to the academic staff on different tracks:

- Teaching skills and learning theories.

- Instructional design.

- Technology- rich classrooms.

- Technology-Based Assessment.

- E-Learning fundamentals.

- Research methodologies.

- Digital resources and research skills.

\section{B. Administration Process}

A preliminary process and the corresponding procedures regarding the registration, students support, teaching and learning, assessment, ... are developed. An automated University Management System (UMS) is developed to support all the administration activities with the university. The UMS components are:

$\begin{array}{ll}\text { - } & \text { Registration } \\ \text { - } & \text { Financial Affairs (Payroll). } \\ \text { - } & \text { Human Resources. } \\ \text { - } & \text { Purchasing and Stock Control. }\end{array}$

The UMS can be accessed locally through the university local area network and remotely through the university portal, taking consideration all the necessary security means.

\section{IV.7 Partnership and Cooperation}

Distance education and e-learning can be deployed to expand provision of higher education in both developing and developed countries, but it cannot be done without considerable investment and the appropriate technical and administrative infrastructure. This means that it is vital to encourage partnership and cooperation to optimize the use of the resources of all those involved. This is an important role for the national higher education system. A national infrastructure for e-learning is recommended to:

- Optimize the use of the resources of all partners involved.

- Exchange experiences.

- Build capacity of staff through collaboration on joint activities.

- Accredit and recognize credentials.

The fact that open and e-learning universities operate in a borderless environment outside their local or national boundaries raises an important concern related to the following issues:

- International quality assurance and accreditation.

- Recognition of certificates and qualifications.

Cooperation agreements were signed with some Egyptian governmental Universities to exchange resources, experience, experts, and facilities. This permits EELU to have learning centers within their campuses. EELU offers joint certificates in collaboration with reputable international universities in Europe and Canada related to different disciplines (information technology, business administration, political sciences, engineering, ....) and different levels of education (undergraduate, and postgraduate). This permits 

learned lessons in applying e-learning in these universities.

\section{Conclusion}

EELU adopts a learning/teaching model based on an e-learning model and supported by an e-university framework. The main objectives are to enhance the quality of higher education by applying information and communication technology in a distinguished education model, expand the number of higher-education students without having to increase the physical universities campuses, expand the number of students each professor can handle without compromising quality. The adopted learning and teaching model facilitates transition from teacher-centered pedagogy, facilitates quality assurance, and facilitates flexible studies opening for more continuing education and life-long learning. Applying an e-university framework reduces costs for students by enabling them to stay where they live and work, facilitates mobility and joint study programs, facilitates mutual recognition of competence, reduces the sense of isolation many traditional distance students experience, and thereby reduces the high drop-out rates associated with distance education.

\section{REFERENCES}

[1] Susan D’Antoni, “The Virtual University: Messages, and Lessons Learned”, UNESCO, 2006.

[2] Mark Notess, and Lesa Lorenzen-Huber, "Online Learning for Seniors: Barriers and Opportunities", eLearn Magazine, ACM, 2007.

[3] Thomas M. Duffy, and Jamie R. Kirkley (Eds.), "Learner-Centered theory and practice in distance education: Cases from higher education", Lawrence Erlbaum Associates, 2004.

[4] Kim, K-J., Bonk, C.J., and Zeng, T., "Surveying the Future of Workplace E-learning: The Rise of Blending, Interactivity, and Authentic Learning", eLearn Magazine", ACM, 2005.

[5] Rostanin, O., Schewe, K.-D., Thalheim, B., and Tretiakov, A., "Managing the data in electronic learning systems", Proceedings of the IEEE International Conference on Advanced Learning Technologies, ICALT, IEEE Computer Society, 2004.

[6] Klaus-Dieter Schewe et al., "A Conceptual View of Web-Based E-Learning Systems", Education and Information Technologies, Springer Science + Business Media, 2005.

[7] Bergstedt, S., Wiegreffe, S., Wittmann, J., and M"oller, D., "Content management systems and e-learning systems: A symbiosis", IEEE International Conference on Advanced Learning Technologies, ICALT, IEEE Computer Society, 2003. 